\title{
Effect of Process Parameters on Mechanical Properties of Friction Stir Spot Welded Magnesium to Aluminum Alloys
}

\author{
H.M. Rao, W. Yuan ${ }^{*}$ and H. Badarinarayan \\ Research \& Development Division, Hitachi America Ltd., 34500 Grand River Avenue, \\ Farmington Hills, MI 48335, USA \\ *Corresponding author. Tel: +1 2484742800 Ext: 1513; fax: +1 2484738420. \\ E-mail: wei.yuan@hitachi-automotive.us (W. Yuan)
}

\begin{abstract}
Friction stir spot welding was applied to dissimilar cast magnesium (Mg) alloy AM60B and wrought aluminum (Al) alloy 6022-T4 under various welding conditions. The influence of tool rotation rate and shoulder plunge depth on lap-shear failure load was examined. Welds were made at four different tool rotation rates of 1000, 1500, 2000 and 2500 revolution per minute (rpm) and various tool shoulder plunge depths from $0 \mathrm{~mm}$ to $0.9 \mathrm{~mm}$. The cross section of each weld exhibited the formation of intermetallic compounds (IMCs) in the stir zone. An increase in tool rotation rate decreased the width of the stir zone and resulted in lower lap-shear failure loads. The stir zone width increased and interlocking of IMCs was observed with an increase in tool shoulder plunge depth at $1000 \mathrm{rpm}$. High lap-shear failure loads were achieved in welds having a large stir zone width with formation of discontinuous IMCs at the tip of the interfacial hook. An average lap-shear failure load of $2.5 \mathrm{kN}$ was achieved for welds made at $1000 \mathrm{rpm}$ and $0.9 \mathrm{~mm}$ shoulder plunge. The present study suggests that the mechanical properties of dissimilar friction stir spot welded alloys
\end{abstract}


are greatly influenced by the stir zone width, interfacial hooks and IMCs which are all weld process dependent.

Keywords: friction stir spot welding; dissimilar alloys; Mg alloy; Al alloy; Intermetallic compounds; Lap-shear strength

\section{Introduction}

Automotive industries around the globe have increased the application of lightweight $\mathrm{Mg}$ and $\mathrm{Al}$ alloys in place of steel to produce more economical and better performing vehicles [1]. The traditional joining method used in automotive industry is resistance spot welding, which works well for steel but is not suitable for $\mathrm{Al}$ or $\mathrm{Mg}$ alloys [1-3]. Friction stir spot welding (FSSW) is a variant of the friction stir welding (FSW) process, a solid-state welding technique developed by The Welding Institute, UK in 1991[4]. A typical FSSW setup consists of a rotating tool with a probe pin that is plunged into two sheets of metal to be joined. The downward force and rotational speed of the tool generates localized friction as the tool interacts with the sheets. The heat generated by friction and plastic deformation of sheet metals softens the materials adjacent to the tool and form a solid bond between upper and lower sheets [5]. Essentially the welding parameters such as the tool rotation rate, tool shoulder plunge depth and dwell time determine the heat generation, joint formation and mechanical properties [6,7]. In addition to welding parameters, the weld tool geometry plays a crucial role in material flow and mixing. Tools with concave tool shoulder designs are found to produce weld joints with higher static strength compared to tools with convex 
or flat tool shoulders $[6,8,9]$. The effect of tool pin design on the weld strength of the FSSW joints has been well documented [6,9-11]. FSSW are characterized by unique features known as the interfacial hooks formed at the faying surface. This hooking feature is a result of trapped oxide films that are displaced upward due to the plastic flow of the material resulting from the downward plunge of the pin into the lower sheet. The interfacial hooks have been shown to influence the failure load of the weld. A smaller hook height is observed to lead to better mechanical properties compared to welds with relatively large hook height [12-15]. The degree of oxide distribution at the faying surface is greatly influenced by the tool geometry and tool rotation rate [16].

Most research conducted on FSSW is relatively confined to joining of similar alloys of Al or Mg. To utilize the optimum physical, mechanical and chemical properties of these alloys, there is increased interest to use of $\mathrm{Al}$ and $\mathrm{Mg}$ in combination. The challenge of joining these dissimilar alloys lies in the formation of the brittle intermetallic compounds (IMCs) in the stir zone along with the geometrical features of the weld. With limited research conducted in solid-state joining of dissimilar alloys, most have reported about the formation IMCs and its effect on the weld joint strength [17-23]. Constitutional liquefaction occurred in the joints during the welding of $\mathrm{Mg}$ and $\mathrm{Al}$ alloys and the $\mathrm{IMCs}\left(\mathrm{Al}_{12} \mathrm{Mg}_{17}, \mathrm{Al}_{3} \mathrm{Mg}_{2}\right)$ were produced at the weld interface [19-23]. These IMCs are brittle and much harder compared to the base material and act as sites for easy crack growth. In FSSW of AA5083 to AZ31, presence of a thick layer of IMCs in a defect-free weld was reported. The thickness of the IMCs was observed to have negligible influence on the lap-shear strength 
of the weld but the distribution of these IMCs did affect the weld strength [17]. On the contrary, in FSSW of AA6K21 and AZ31, the lap-shear strength of welds decreased with increased thickness of the IMCs layer [19]. This reduction in strength was observed due to cracking in IMCs as the frictional heat increased with increase in tool rotation rate and dwell time. Similar relationship between lap-shear strength and the thickness of IMCs has been noticed in FSW of AZ31B and AA5083, due to weakened mechanical interlock between $\mathrm{Mg}$ and $\mathrm{Al}$ alloys [20]. In cyclic testing of FSSWed dissimilar AZ31 to AA5754, the failure occurred due to nugget debonding where the IMCs layer was present [23]. Yin et al. [24] observed that the distance from the tip of the hook to the keyhole periphery influenced the strength of FSSWed AZ91 to AZ31 Mg alloys. This distance greatly increased for welds made using tool having a triangular threaded pin compared to welds made using a non-threaded pin tool. In general, welds made with triangular pin tools have displayed larger bond width and better lap-shear strength compared to welds made using cylindrical pin tools $[6,25]$. While limited work has been done on FSSW of dissimilar Al and $\mathrm{Mg}$ alloys, and the fundamental understanding of critical role of IMCs on weld strength is still lacking, an effort has been made to explore the influence of the welding conditions on IMCs formation as well as lap-shear tensile properties between spot welded cast AM60B and rolled AA6022-T4.

\section{Experimental Procedure}

A super vacuum die cast AM60B Mg plate having a thickness of $3.1 \mathrm{~mm}$ was FSSW to 1.5 mm-thick rolled AA6022-T4 sheet. The FSSW tool used in this study as shown in Fig. 1 
was made of standard tool steel (H13) and constituted a concave tool shoulder and a triangular pin with threaded groove surface. The geometrical features and dimensions of the FSSW tool are listed in Table 1. FSSW was conducted in such a configuration that the $\mathrm{Mg}$ plate was always on top of the $\mathrm{Al}$ sheet with lap-shear tensile specimens having a $30 \mathrm{~mm} \times$ $30 \mathrm{~mm}$ overlap between the two materials as shown in Fig. 2.

One of the research goals of this study is to identify the ideal welding parameters for optimal weld strength. The course of isolating the weld process parameters was carried out in two stages; stage I, the optimum weld tool rotation rate was quantified and in stage II, the ideal tool shoulder plunge depth was identified. In stage I, a set of FSSW coupons were prepared at different tool rotation rates, 1000/1500/2000/2500 rpm and tool shoulder plunge depth of $0.2 / 0.4 / 0.6 \mathrm{~mm}$. The coupons were subjected to tensile testing and the optimum tool rotation rate was identified based on the weld strength. In stage II, the final set of FSSW coupons were prepared using the tool rotation rate quantified in stage I and then by varying the tool shoulder plunge depth. The process window indicating various welding parameters employed in this two-stage study is shown in Table 2. A constant tool plunge speed of $12 \mathrm{~mm} / \mathrm{min}$ was maintained in both stages of the welding.

The lap-shear tensile tests were conducted at room temperature on an Instron screw-drive machine (Model 1123) with a constant cross head speed of $2 \mathrm{~mm} / \mathrm{min}$. At each stage of study, selected tested and un-tested coupons were cross-sectioned through the center of the welds and cold mounted in epoxy. The mounted specimens were mechanically ground and 
polished with $0.05 \mu \mathrm{m}$ final finish for weld geometry, IMCs and failure mode analysis. In order to reveal the microstructure and IMCs, the AA6022-T4 was first etched with 20\% $\mathrm{NaOH}$ solution (caustic etching) and then AM60B was etched using an acetic picral solution (4.2 g picric acid, $10 \mathrm{ml}$ acetic acid, $10 \mathrm{ml} \mathrm{H}_{2} \mathrm{O}$, and $70 \mathrm{ml}$ ethanol). The macro and microstructures of welds and failure modes were analyzed using the optical microscope. To further analyze the IMCs and its composition, untested FSSW coupons were examined under Jeol 7600F scanning electron microscope (SEM) with energy-dispersive $\mathrm{x}$-ray spectroscopy (EDS) capabilities.

The microstructures of the as-received cast AM60B and AA6022-T4 are shown in Fig. 3. The microstructure of cast AM60B is comprised of a combination of irregular sized globular grains and large dendrites. Pores or voids were also observed all through the cast sheet. The AA6022-T4 Al alloy shows large globular grains on the surface and elongated grains along the rolling direction of the sheet.

\section{Results and Discussion}

To isolate the ideal tool rotation rate, welded coupons were produced under different welding parameters and lap-shear tested. Fig. 4 presents the average failure load value with one standard deviation as a function of tool shoulder plunge depth at various tool rotation rates. The results show that welds made at $1000 \mathrm{rpm}$ had higher failure loads compared to welds made at other tool rotation rates when the shoulder plunge depth is between 0.2 and $0.6 \mathrm{~mm}$. Though there is slight scatter in the results for each individual welded coupon, the 
failure load decreased gradually with increase in tool rotation rate. The decrease in failure load as a function of tool rotation rate can be attributed to the size and microstructure of stir zone as well as the hook features of the faying surface. It has been well-documented in FSSW of similar alloys that the tool rotation rate and tool shoulder plunge depth influence the hooking geometry and microstructure which in-turn affect the mechanical properties $[12,15,24,26-28]$. Since in stage I the identification of the ideal tool rotation is the primary goal, the influence of the tool rotation rate on mechanical properties of welds will be discussed. The influence of the tool shoulder plunge depth on mechanical properties of welds will be discussed later in this section.

\subsection{Influence of tool rotation rate on mechanical property and macro features of the weld}

One of the major issues in welding dissimilar materials is the formation of IMCs in the stir zone [18-20,29-31]. Tool rotation rate which dominates the frictional heat generation has shown to greatly influence the formation of IMCs [17,19]. For brevity, the discussion on formation of IMCs with respect to tool rotation rate will not be discussed and rather the macro features such as the hook geometry, the weld bond width and stir zone will be emphasized. The cross section analysis of untested weld coupons suggests that the failure load are highly influenced by the size of stir zone, hook geometry and weld bond width. Fig. 5 compares cross-sections of untested welds made at $0.6 \mathrm{~mm}$ tool shoulder plunge depth but various tool rotation rates. Fig. 5(a), (b) and (c) show macrographs of the weld cross section and the numbered box in each picture indicates the stir zone which is enlarged and presented in Fig. 5(d), (e) and (f) respectively. The distance from the tip of hook to key- 
hole interface is addressed as the weld bond width. It is evident from Fig. 5(d), (e) and (f) that geometrical features like bond width, stir zone size, hook height and orientation vary from one weld to another, indicating the dominant influence of tool rotation rate on material flow and mixing.

In the current study, the stir zone size and weld bond width of welds decreased with increase in the tool rotation rate. Similar phenomena have been reported in FSSW of Mg alloy [32]. The weld bond width is the region in the weld nugget where a complete bonding of materials occurs when plastically deformed material from the upper and lower sheets flows and mixes together with the aid of the probe pin. The amount of plastic deformation is dominated by the amount of frictional heat generated. During FSSW, the major portion of frictional heat is generated when the tool shoulder comes into contact with the upper sheet and the amount of frictional heat generated is influenced by the tool rotation rate. While the tool shoulder predominantly determines the frictional heat generated, the probe pin influences the material flow and mixing during the FSSW [6,12,25,27]. Increasing the tool rotation rate introduces higher frictional heat $[16,33,34]$ and strain rate $[33,34]$ in the weld nugget. This reduces the viscosity of the material right under the tool shoulder and material adjacent to the pin in the key-hole region [32]. The reduced viscosity sabotages the material mixing in the stir zone by introducing slippage between the pin and the material adjacent to it. The function of the pin which is to stir and mix the materials from upper and lower sheets is thus weakened. This is clearly evident from Fig. 5(e) and (f) where the stir zone becomes narrower and the weld bond width reduces as the soft material from the 
bottom of the pin is extruded and flows locally around the periphery of the key-hole. With a weaker bonding and narrower stir zone, the welds failed in much lower loads. At $1000 \mathrm{rpm}$ tool rotation rate, the frictional heat generated is sufficient to plastically deform the material around the pin while maintaining high viscosity between the pin surface and the material around it. Material immediately adjacent to the pin sticks to the pin surface and rotates at the same rate as the tool which results in breaking of sheet interface and mixing of materials from the upper and lower sheets [35], thus a large weld bond width and stir zone are seen in Fig. 5(d). While the stir zone size or weld bond width is one of the factors that influence the lap-shear strength of the welds, the role of hook geometry will be investigated.

During FSSW, trapped oxide films present between the overlapping sheets are often displaced in an upward direction towards the upper sheet into a "hook-like" shape. This hooking is largely due to the plastic flow of the material resulting from the downward plunge of the pin into the lower sheet [15]. In FSSW higher joint strengths were found when the hooks oriented outwards from tool rotation axis and away from the key-hole compared to hooks that terminated very close to the key-hole $[6,13,24,25]$. The bold arrows in Fig. 5(d), (e) and (f) indicate the end of the hook in each weld and the distance from the tip of the hook to the key-hole interface is defined as the weld bond width (highlighted in dotted line). Yin et al. [24] indicated that the lap-shear strength of spot welds between AZ91 and AZ31 increased as the weld bond width increased. It is evident from Fig. 5(d) that the hook orients outwards from the tool axis and terminates away from the key-hole for welds made at $1000 \mathrm{rpm}$. With the increase in tool rotation rate $(1500 \mathrm{rpm}$ and $2000 \mathrm{rpm})$, 
the hook orients towards the tool axis and terminates much closer to the key-hole as seen in Fig. 5(e) and (f). At higher tool rotation rates (2000 rpm), the hook was continuous up to till the key-hole which indicates that the softer material in the bottom Al sheet was simply extruded without breaking the oxide layer in the bottom sheet. In other words the top $\mathrm{Mg}$ and bottom $\mathrm{Al}$ sheet did not mix in general and a clear bifurcation at the faying surface existed indicating insufficient bonding between the two sheets. These interfacial hooks act as preexisting cracks and the failure of the welds occurred when the crack progressed through the tip of the hook to the nearest free surface $[6,12,14,15,25]$.

\subsection{Influence of tool shoulder plunge depth on formation of IMCs and weld bond width}

With the isolation of the tool rotation rate in the first stage, the task was to identify the ideal tool shoulder plunge depth. Fig. 6 presents the lap-shear tensile result for welds produced at $1000 \mathrm{rpm}$ and various tool shoulder plunge depths. It is important to note that the load increased statistically significantly with the increase in plunge depth. This is attributed to weld geometric features as well as the formation of IMCs. Since most of the welds in this study failed when cracks propagated from the interfacial hook into the key-hole through the stir zone and ultimately detached due to shear overload, the influence of effective upper sheet thickness on failure load is not of importance. Hence the weld bond width and hook geometry are analyzed. Few studies on FSSW of similar alloys $[6,36,37]$ have indicated that the increase in plunge depth improved tensile strength of the welds. Similar findings have also been reported for FSSW of dissimilar metals[17,18]. The increase in plunge depth during FSSW of dissimilar metals increased the formation of IMCs and at the same 
time formed a strong interlock bond thereby improving the weld strength. Yin et al. [13] proposed that the weld strength in FSSW can be increased if welds are produced with large bond width and smaller hook height and larger effective sheet thickness.

The transverse cross-sections of untested and unetched representative welds produced under various tool shoulder plunge depths are shown in Fig. 7. Fig. 7(a), (b) and (c) present cross sections of welds produced at $0.0 \mathrm{~mm}, 0.6 \mathrm{~mm}$ and $0.9 \mathrm{~mm}$ tool shoulder plunge depth respectively and the rectangular box in each picture indicates the stir zone which is enlarged and shown in Fig. 7(d), (e) and (f) respectively. It is quite evident that the stir zone size increased with increase in tool shoulder plunge depth. It has to be noted that the thickness of the upper sheet $(\mathrm{Mg})$ is $3.1 \mathrm{~mm}$ which is twice the thickness of the lower $\mathrm{Al}$ sheet. As previously discussed, the bold arrow in each figure indicates the ending of interfacial hook and the horizontal dotted line highlights the approximate weld bond width in each weld. The weld bond width increased with increase in tool shoulder plunge depth as the Al from the lower sheet was extracted and pushed upwards towards the upper sheet where it mixed with the Mg forming a strong weld bond. Hence from Fig. 7 it can be inferred that the weld bond width increased with increase in tool plunge depth and the interfacial hook terminated away from the key-hole surface and thereby increasing the weld strength.

As discussed earlier in this section, one of the other important factors that influence the weld strength in a dissimilar weld is the formation of IMCs. The formation of IMCs during 
FSSW and FSW of Mg and Al alloys has been discussed in detail elsewhere [17,19-22,29]. The two IMCs that are often observed during welding of $\mathrm{Mg}$ and $\mathrm{Al}$ alloys are $\mathrm{Al}_{3} \mathrm{Mg}_{2}$ and $\mathrm{Al}_{12} \mathrm{Mg}_{17}$ respectively in $\mathrm{Al}$ rich side and $\mathrm{Mg}$ rich side of the weld. For comparative study only two welding conditions will be discussed, $0.0 \mathrm{~mm}$ and $0.9 \mathrm{~mm}$ plunge depth at 1000 rpm. Fig. 8 indicates the different regions identified in the stir zone of the weld. Though visually each phase can be distinguished from each other, EDS was performed on all the samples to clarify the composition. To keep the discussion simple, only representative compositions of different phases/regions are mentioned in Table 3.

Fig. 9 presents microstructure and IMCs formed in the weld produced at $0.0 \mathrm{~mm}$ shoulder plunge. Fig. 9(a) shows an overview of cross section with several areas of interest (S1, S2, S3 \& S4) highlighted by rectangular boxes . Fig. 9(b) shows a magnified view of region S1 (the weld bond width region). It is evident the bonding of $\mathrm{Mg}$ and $\mathrm{Al}$ sheet exists in form of a mechanical interlock between the IMCs and the top Mg sheet. The interlocking of IMCs with native metal has shown to improve the weld strength $[20,29,38]$. The darker region in the stir zone is composed of $\mathrm{Al}_{12} \mathrm{Mg}_{17}$ and the lighter region mostly around the periphery of the stir zone is composed of $\mathrm{Al}_{3} \mathrm{Mg}_{2}$ as indicated in Fig. 9(b) and 9(c) (region S2). The bold arrow in Fig. 9(c) indicates the point where the interfacial hook terminates, after which there exists continuing phase between the $\mathrm{Mg}$ alloy and $\mathrm{Al}_{3} \mathrm{Mg}_{2}$ which extends into the stir zone forming an interlock with the $\mathrm{Al}_{12} \mathrm{Mg}_{17}$. Fig. 9(d) (region S3) shows the region where the interfacial hook exists which is formed when the Al alloy from the bottom sheet is extracted upwards into the Mg alloy. The interfacial hook forms and leads to a weak bond 
with the presence of the $\mathrm{Al}_{3} \mathrm{Mg}_{2}$ between the two materials (Fig. 10(d), (e)). Similar to FSSW of same metals, there exists an unbounded region at the faying surface of the two sheets as seen in Fig. 9(e) (region S4).

SEM images in Fig. 10 provide a better perspective of the regions of interest clearly differentiating the various regions in the stir zone. $\mathrm{Al}_{12} \mathrm{Mg}_{17}$ is distinguished as the darker region and $\mathrm{Al}_{3} \mathrm{Mg}_{2}$ is the lighter region at the periphery of the stir zone. Sato et al. [17] reported similar contrast between the two IMCs. Fig. 10(b) (region S5) is the region at top of the stir zone and the enlarged section of the dotted rectangular region is shown in Fig. 10(c) which presents the mechanical interlocking between the native $\mathrm{Mg}$ alloy and the IMCs in the stir zone. As mentioned earlier the interfacial hook is composed of the extruded Al alloy which forms a kissing bond with the Mg alloy as shown in Fig. 10(d) (region S6). The dotted rectangular box region is enlarged to show the presence of the thin shiny layer of $\mathrm{Al}_{3} \mathrm{Mg}_{2}$ at the interface between the hook and the $\mathrm{Mg}$ alloy. Previous studies have shown the formation of a thin layer of $\mathrm{Al}_{12} \mathrm{Mg}_{17}$ at the interface of the two sheets $[17,19,21]$. In the current study $\mathrm{Al}_{3} \mathrm{Mg}_{2}$ is formed at the interface between the $\mathrm{Al}$ and $\mathrm{Mg}$ sheets which may be due to the fact that the Al alloy is extruded upwards and constitutionally contributes to a greater concentration compared to $\mathrm{Mg}$.

For welds made at $0.9 \mathrm{~mm}$ tool shoulder plunge depth, the formation of IMCs was similar to what has been observed at $0.0 \mathrm{~mm}$ plunge depth. One of the primary differences is the increase in stir zone size and weld bond width as previously discussed. Fig. 11(a) shows the 
transverse cross section of etched weld with numerous rectangular boxes indicating the area of interests in the stir zone (T1, T2, T3 \& T4). Fig. 11(b) (region T1) presents the weld bond width region with IMCs forming a mechanical interlock with the native $\mathrm{Mg}$ alloy. Compared to welds produced at $0.0 \mathrm{~mm}$ plunge depth, the weld bond width and the size of the IMCs is much larger in welds produced at $0.9 \mathrm{~m}$ plunge depth. Lee et al. [18] indicated that the tensile strength of FSSW steel and Al-Mg alloy increased with plunge depth. With an increase in plunge depth, the stir zone size of the weld increased and the bonding of the native alloy with the IMCs in the stir zone increased. In this study the strong bonding in the weld region as mentioned earlier is partially due to mechanical interlocking between $\mathrm{Mg}$ alloy and the IMCs in the stir zone. As seen in Fig. 11(b), the Mg alloy (top sheet) forms a mechanical interlock with the IMCs in the stir zone. The IMCs at the interface of the weld produced at $0.9 \mathrm{~mm}$ are thicker and continuous, but thinner and discontinuous at the weld bond width region. IMCs reduce the weld strength any time they present a lower energy path for crack propagation compared to the surrounding matrix. Thinner and discontinuous IMCs in the weld bond region provide better ductility compared to continuous thicker IMCs and thereby increasing the tensile strength of the welds [19,20,38]. In Fig. 11(c) (region T2) the bold arrow indicates the termination of the interfacial hook. It is clearly seen that the hook terminates away from the keyhole surface thereby increasing the weld bond width. Similar to welds produced at $0.0 \mathrm{~mm}$ plunge depth, the region T3 in Fig. 11(d) and T4 in Fig. 11(e) shows the interfacial hook formed by the extruded Al alloy and the unbonded region at the faying surface. 
Fig. 12 presents SEM images of the stir zone. Fig. 12(a) shows the etched cross section with rectangular boxes indicating region of interest (T5 \& T6). The weld bond width region seen in Fig. 12(b) (region T5) shows many small agglomerates of $\mathrm{Al}_{12} \mathrm{Mg}_{17}$ at the periphery or boundary of the stir zone and some band structures of $\mathrm{Al}_{12} \mathrm{Mg}_{17}$ just below the periphery. This is evident in Fig. 12(c) where the agglomerates of $\mathrm{Al}_{12} \mathrm{Mg}_{17}$ are formed simultaneously with the continuing $\mathrm{Al}_{3} \mathrm{Mg}_{2}$. The darker regions are the $\alpha-\mathrm{Mg}+\mathrm{Al}_{12} \mathrm{Mg}_{17}$ eutectic structures formed due to the constitutional liquation mechanism [17,29]. In Fig. 12(d) (region T6) the interfacial hook terminates just before the weld bond width (indicated by bold arrow). An enlarged view of the area indicated in the dotted rectangular box in Fig. 12(d) is shown in Fig. 12(e). The interfacial hook is formed by the extruded Al alloy and a thin layer of $\mathrm{Al}_{3} \mathrm{Mg}_{2}$ is formed between the outer layer of the hook and the $\mathrm{Mg}$.

\subsection{Crack propagation and failure mechanisms of welds during lap-shear testing}

The cross sections of tested specimens in Fig. 13(a) and (b) indicate that cracks propagate from the weak interfacial hook through the stir zone of welds. The regions indicated in the rectangular box in Fig. 13(a) and (b) are magnified to show the crack propagation in the weld stir zone in Fig.14 and Fig.15 respectively.

The failure mode in both welds is very similar. Once the crack grows halfway around the keyhole, the weld fails due to shear overload through the other side of the weld. Fig. 14(a) and Fig. 15(a) are macrographs of the weld region with primary crack (PC) propagating through the faying surface and along the interfacial hook, and finally reaching the keyhole 
surface. The cracking through the base of the stir zone on the other side of the weld indicates the shear over load failure (SOF). The brittle thin layer of $\mathrm{Al}_{3} \mathrm{Mg}_{2}$ at the interface of the hook and the $\mathrm{Mg}$ alloy provides an easy path for the already existing crack to propagate without any hindrance as seen in Fig. 14(c) and Fig. 15(c). Once the PC reaches the tip of the interfacial hook, interlocking of the $\mathrm{Al}_{3} \mathrm{Mg}_{2}$ in the stir zone with dispersed $\mathrm{Al}_{12} \mathrm{Mg}_{17}$ gives resistance for the crack to propagate effortlessly. From Fig. 14(b) it is evident that the thick continuous IMCs formed at the periphery of the stir zone coupled with smaller weld bond width provided an easier path for the PC to propagate resulting in lower lap-shear failure load. In Fig. 15(b) discontinuous IMCs coupled with larger weld bond width provided higher resistance for the PC to propagate which resulted in welds with higher failure load. The study indicates that the formation of IMCs and the weld geometry together influence the lap-shear strength of dissimilar welds.

\section{Conclusions}

In this study the effect of welding parameters on mechanical properties of friction stir spot welded dissimilar alloys was investigated. An optimum process condition for FSSW of cast $\mathrm{Mg}$ alloy to wrought $\mathrm{Al}$ alloy was identified. The following conclusions are made:

1) It is feasible to FSSW cast AM60B Mg alloy to AA6022-T4 Al alloy with good mechanical properties under certain welding parameters for a triangular pin tool. 
2) With the increase in tool rotation rate for the same tool plunge depth, the weld bond width decreased due to localized material flow and reduced material mixing in the stir zone. This decrease in weld bond width results in lower lap-shear failure load.

3) The lap-shear failure load increased with increase in tool shoulder plunge depth at 1000 rpm tool rotation rate partially due to increased weld bond width.

4) The lap-shear failure load of FSSW dissimilar welds depends on both the geometrical features of welds which affect the weld bond width and interlocking as well as the formation of IMCs in the stir zone. A continuous layer of IMCs resulted in reduced weld strength while discontinuous IMCs resulted in improved weld strength.

5) Both geometrical features and IMCs formation are welding parameter dependent, such as the tool rotation rate and tool shoulder plunge depth. With proper welding parameter development, it is possible to produce sound FSSW joints in dissimilar Mg and $\mathrm{Al}$ alloys.

\section{Acknowledgments}

The authors acknowledge the United States Automotive Materials Partnership (USAMP) Magnesium Front End R\&D project for support. This material is based upon work supported by the Department of Energy, Office of Energy Efficiency and Renewable Energy Vehicle Technologies Program under Award Number No. DE-EE0005660. This report was prepared as an account of work sponsored by an agency of the United States Government. Neither the United States Government nor any agency thereof, nor any of their employees, makes any warranty, express or implied, or assumes any legal liability or 
responsibility for the accuracy, completeness, or usefulness of any information, apparatus, product, or process disclosed, or represents that its use would not infringe privately owned rights. Reference herein to any specific commercial product, process, or service by trade name, trademark, manufacturer, or otherwise does not necessarily constitute or imply its endorsement, recommendation, or favoring by the United States Government or any agency thereof. The views and opinions of authors expressed herein do not necessarily state or reflect those of the United States Government or any agency thereof.

\section{References}

[1] Cole GS, Sherman AM. Lightweight Materials for Automotive Applications. Mater Charact 1995:3-9.

[2] Thornton P., Krause AR, Davies RG. The Aluminum Spot Weld. Weld J 1996;75:101s-108s.

[3] Gean A, Westgate SA, Kucza JC, Ehrstrom JC. Static and Fatigue Behavior of SpotWelded 51 82-0 Aluminum Alloy Sheet. Weld Journal- New York 1999;78:80s-86s.

[4] Thomas W., Nicholas E., Needham J., Murch M., Templesmith P, Dawes C. Frcition Stir Butt Welding. G.B. Patent 9125978.8, 1991.

[5] Wang D-A, Chen C-H. Fatigue lives of friction stir spot welds in aluminum 6061-T6 sheets. J Mater Process Technol 2009;209:367-75.

[6] Badarinarayan H, Shi Y, Li X, Okamoto K. Effect of tool geometry on hook formation and static strength of friction stir spot welded aluminum 5754-O sheets. Int J Mach Tools Manuf 2009;49:814-23.

[7] Gerlich A, Su P, North TH. Tool penetration during friction stir spot welding of Al and Mg alloys. J Mater Sci 2005;40:6473-81.

[8] Lin P, Pan J, Pan T. Failure modes and fatigue life estimations of spot friction welds in lap-shear specimens of aluminum 6111-T4 sheets. Part 2: Welds made by a flat tool. Int J Fatigue 2008;30:90-105. 
[9] Yang Q, Li X, Chen K, Shi YJ. Effect of tool geometry and process condition on static strength of a magnesium friction stir lap linear weld. Mater Sci Eng A 2011;528:2463-78.

[10] Yuan W, Mishra RS, Webb S, Chen YL, Carlson B, Herling DR, et al. Effect of tool design and process parameters on properties of Al alloy 6016 friction stir spot welds. J Mater Process Technol 2011;211:972-7.

[11] Chowdhury SM, Chen DL, Bhole SD, Cao X. Tensile properties of a friction stir welded magnesium alloy: Effect of pin tool thread orientation and weld pitch. Mater Sci Eng A 2010;527:6064-75.

[12] Yin YH, Sun N, North TH, Hu SS. Hook formation and mechanical properties in AZ31 friction stir spot welds. J Mater Process Technol 2010;210:2062-70.

[13] Yin YH, Sun N, North TH, Hu SS. Influence of tool design on mechanical properties of AZ31 friction stir spot welds. Sci Technol Weld Join 2010;15:81-6.

[14] Jordon JB, Horstemeyer MF, Daniewicz SR, Badarinarayan H, Grantham J. Fatigue Characterization and Modeling of Friction Stir Spot Welds in Magnesium AZ31 Alloy. J Eng Mater Technol 2010;132:041008.

[15] Rao H., Jordon J., Barkey M., Guo Y., Su X, Badarinarayan H. Influence of structural integrity on fatigue behavior of friction stir spot welded AZ31 Mg alloy. Mater Sci Eng A 2013;564:369-80.

[16] Chang CI, Lee CJ, Huang JC. Relationship between grain size and Zener-Holloman parameter during friction stir processing in AZ31 Mg alloys. Scr Mater 2004;51:509-14.

[17] Sato YS, Shiota a., Kokawa H, Okamoto K, Yang Q, Kim C. Effect of interfacial microstructure on lap shear strength of friction stir spot weld of aluminium alloy to magnesium alloy. Sci Technol Weld Join 2010;15:319-24.

[18] Lee C., Choi D., Yeon Y., Jung S. Dissimilar friction stir spot welding of low carbon steel and Al-Mg alloy by formation of IMCs. Sci Technol Weld Join 2009;14:21620.

[19] Choi D-H, Ahn B-W, Lee C-Y, Yeon Y-M, Song K, Jung S-B. Formation of intermetallic compounds in $\mathrm{Al}$ and $\mathrm{Mg}$ alloy interface during friction stir spot welding. Intermetallics 2011;19:125-30.

[20] Yamamoto N, Liao J, Watanabe S, Nakata K. Effect of Intermetallic Compound Layer on Tensile Strength of Dissimilar Friction-Stir Weld of a High Strength Mg Alloy and Al Alloy. Mater Trans 2009;50:2833-8. 
[21] McLean A., Powell GLF, Brown IH, Linton VM. Friction stir welding of magnesium alloy AZ31B to aluminium alloy 5083. Sci Technol Weld Join 2003;8:462-4.

[22] Chen YC, Nakata K. Friction stir lap joining aluminum and magnesium alloys. Scr Mater 2008;58:433-6.

[23] Chowdhury SH, Chen DL, Bhole SD, Cao X, Wanjara P. Lap shear strength and fatigue life of friction stir spot welded AZ31 magnesium and 5754 aluminum alloys. Mater Sci Eng A 2012;556:500-9.

[24] Yin YH, Sun N, North TH, Hu SS. Microstructures and mechanical properties in dissimilar AZ91/AZ31 spot welds. Mater Charact 2010;61:1018-28.

[25] Badarinarayan H, Yang Q, Zhu S. Effect of tool geometry on static strength of friction stir spot-welded aluminum alloy. Int J Mach Tools Manuf 2009;49:142-8.

[26] Solanki KN, Jordon JB, Whittington W, Rao H, Hubbard CR. Structure-property relationships and residual stress quantification of a friction stir spot welded magnesium alloy. Scr Mater 2012;66:797-800.

[27] Sun N, Yin YH, Gerlich a. P, North TH. Tool design and stir zone grain size in AZ31 friction stir spot welds. Sci Technol Weld Join 2009;14:747-52.

[28] Zhang Z, Yang X, Zhang J, Zhou G, Xu X, Zou B. Effect of welding parameters on microstructure and mechanical properties of friction stir spot welded 5052 aluminum alloy. Mater Des 2011;32:4461-70.

[29] Firouzdor V, Kou S. Formation of Liquid and Intermetallics in Al-to-Mg Friction Stir Welding. Metall Mater Trans A 2010;41:3238-51.

[30] Kou S. Al-to-Mg Friction Stir Welding : Effect of Positions of Al and Mg with Respect to the. Weld J 2009;88:213-24.

[31] Cao XJ, Jahazi M. Friction Stir Welding of Dissimilar AA 2024-T3 to AZ31B-H24 Alloys. Mater Sci Forum 2010;638-642:3661-6.

[32] Yuan W, Mishra RS, Carlson B, Verma R, Mishra RK. Material flow and microstructural evolution during friction stir spot welding of AZ31 magnesium alloy. Mater Sci Eng A 2012;543:200-9.

[33] Gerlich A, Yamamoto M, North T. Strain Rates and Grain Growth in Al 5754 and Al 6061 Friction Stir Spot Welds. Metall Mater Trans A 2007;38:1291-302.

[34] Gerlich A, Su P, North TH. Peak temperatures and microstructures in aluminium and magnesium alloy friction stir spot welds. Sci Technol Weld Join 2005;10:647-52. 
[35] Schmidt H, Hattel J, Wert J. An analytical model for the heat generation in friction stir welding. Model Simul Mater Sci Eng 2004;12:143-57.

[36] Bozzi S, Helbert-Etter a. L, Baudin T, Klosek V, Kerbiguet JG, Criqui B. Influence of FSSW parameters on fracture mechanisms of 5182 aluminium welds. J Mater Process Technol 2010;210:1429-35.

[37] Rao HM, Rodriguez RI, Jordon JB, Barkey ME, Guo YB, Badarinarayan H, et al. Friction stir spot welding of rare-earth containing ZEK100 magnesium alloy sheets. Mater Des 2014;56:750-4.

[38] Firouzdor V, Kou S. Al-to-Mg Friction Stir Welding: Effect of Material Position, Travel Speed, and Rotation Speed. Metall Mater Trans A 2010;41:2914-35. 


\section{Figure Captions}

Fig. 1. Schematic of FSSW tool used in this study.

Fig. 2. Picture of (a) clamp fixture (b) spot welded $\mathrm{Mg}$ to $\mathrm{Al}$ sheets, and (c) geometrical dimensions of the FSSW test coupon.

Fig. 3. Microstructure of the as-received (a) AM60B, (b) and (c) AA6022-T4 in various cross-sectional views (ND: normal direction; RD: rolling direction; TD: transverse direction).

Fig. 4. Lap-shear failure load of welds as a function of tool shoulder plunge depth under various tool rotation rates.

Fig. 5. Representative cross sections of welds made at $0.6 \mathrm{~mm}$ under (a) $1000 \mathrm{rpm}$, (b) $1500 \mathrm{rpm}$ and (c) $2000 \mathrm{rpm}$. Figures (d), (e) and (f) are magnified views of region I, II and III with the bold arrow indicating termination of the hook and the dotted line indicating the weld bond width.

Fig. 6. Lap-shear failure load of welds as a function of tool shoulder plunge depth at 1000 rpm.

Fig. 7. Representative cross sections of welds produced at $1000 \mathrm{rpm}$ and various plunge depths (a) $0.0 \mathrm{~mm}$ (b) $0.6 \mathrm{~mm}$ and (c) $0.9 \mathrm{~mm}$. Figures (d), (e) and (f) are magnified views of region I, II and III with termination of the hook and the weld bond width highlighted.

Fig. 8. SEM image showing different regions in the stir zone. Each region is characterized by using EDS with detailed composition shown in Table 3.

Fig. 9. Microstructure for a weld made at $1000 \mathrm{rpm}$ and $0.0 \mathrm{~mm}$ shoulder plunge (a) macrograph of cross section, (b) region S1 indicating the interlocking in the weld bond width region, (c) region S2 highlighting termination of the hook, (d) region S3 indicating the interfacial hook and (e) region S4 highlighting the unbonded region.

Fig. 10. SEM images of the weld produced at $1000 \mathrm{rpm}$ and $0.0 \mathrm{~mm}$ (a) macrograph of cross section, (b) region S5 indicating the interlocking, (c) magnified view of region S5, (d) region S6 indicating the interfacial hook and (e) magnified view of region S6.

Fig. 11. Microstructures of a weld produced at $1000 \mathrm{rpm}$ and $0.9 \mathrm{~mm}$ shoulder plunge (a) macrograph of cross section, (b) region $\mathrm{T} 1$ indicating the interlocking in the weld bond width region (c) region T2 highlighting termination of the hook (d) region T3 indicating the interfacial hook and (e) region T4 highlighting the unbonded region. 
Fig. 12. SEM images of the weld produced at $1000 \mathrm{rpm}$ and $0.9 \mathrm{~mm}$ (a) macrograph of cross section, (b) region T5 indicating the interlocking, (c) magnified view of region T5, (d) region T6 indicating the interfacial hook and (e) magnified view of region T6.

Fig. 13. Cross sections of tested welds made at $1000 \mathrm{rpm}$ (a) $0.0 \mathrm{~mm}$ and (b) $0.9 \mathrm{~mm}$. The boxes in each picture indicate the stir zone where cracks propagated and failure occurred.

Fig. 14. (a) Macrograph of a tested weld made at $1000 \mathrm{rpm}$ and $0.0 \mathrm{~mm}$ with regions I and II highlighting SOF and PC, and magnified view of (b) the PC propagation in the weld bond width area and (c) the interfacial hook signifying the PC propagation through the IMCs.

Fig. 15. (a) Macrograph of a tested weld made at $1000 \mathrm{rpm}$ and $0.9 \mathrm{~mm}$ with regions III and IV highlighting SOF and PC, and magnified view of (b) the PC propagation in the weld bond width area and (c) the interfacial hook signifying the PC propagation through the IMCs. 


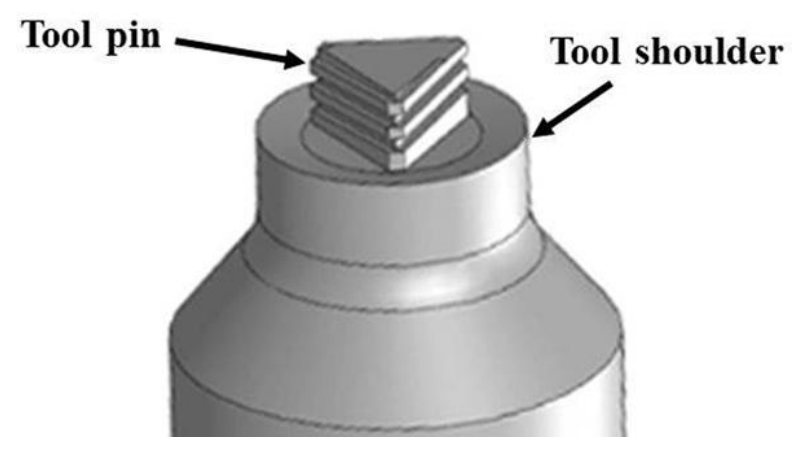

Fig. 1. Schematic of FSSW tool used in this study. 

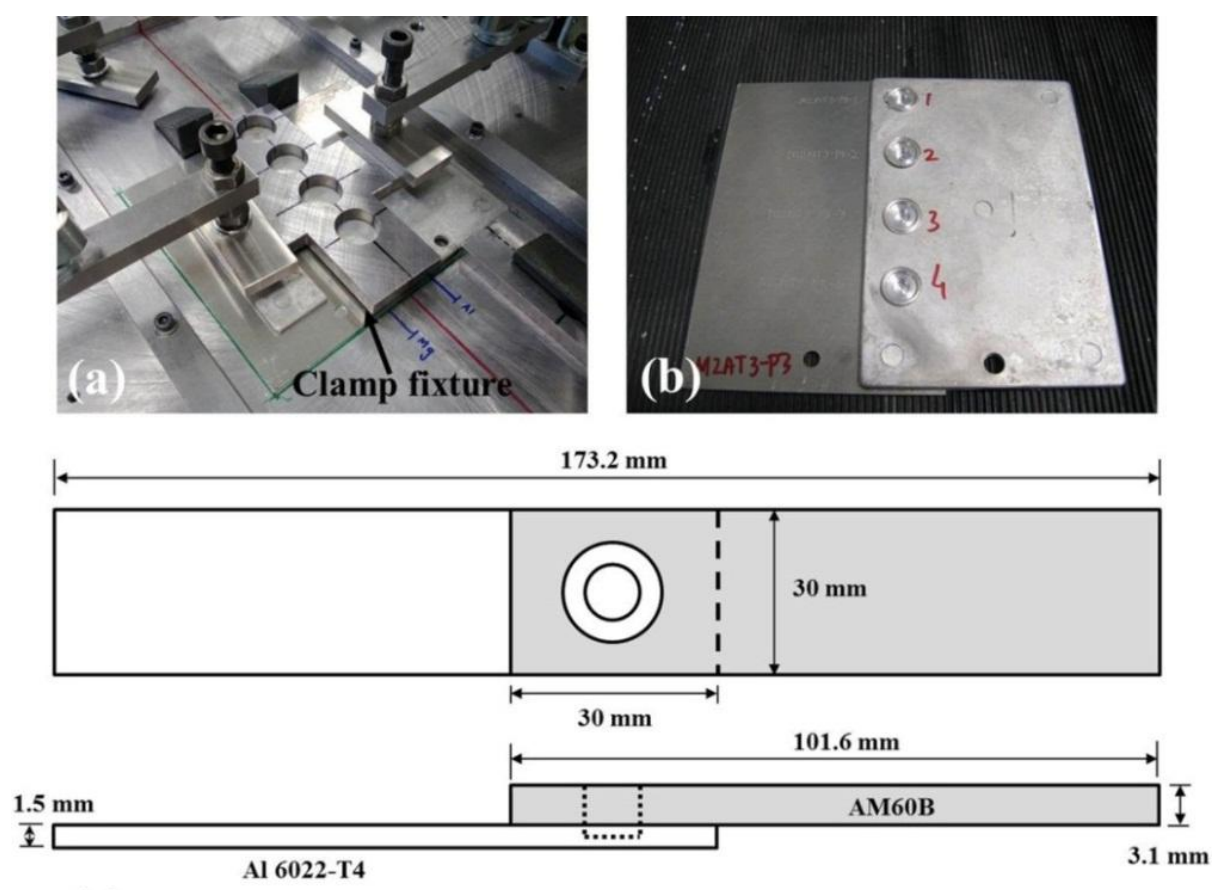

(c)

Fig. 2. Picture of (a) clamp fixture (b) spot welded $\mathrm{Mg}$ to $\mathrm{Al}$ sheets, and (c) geometrical dimensions of the FSSW test coupon. 


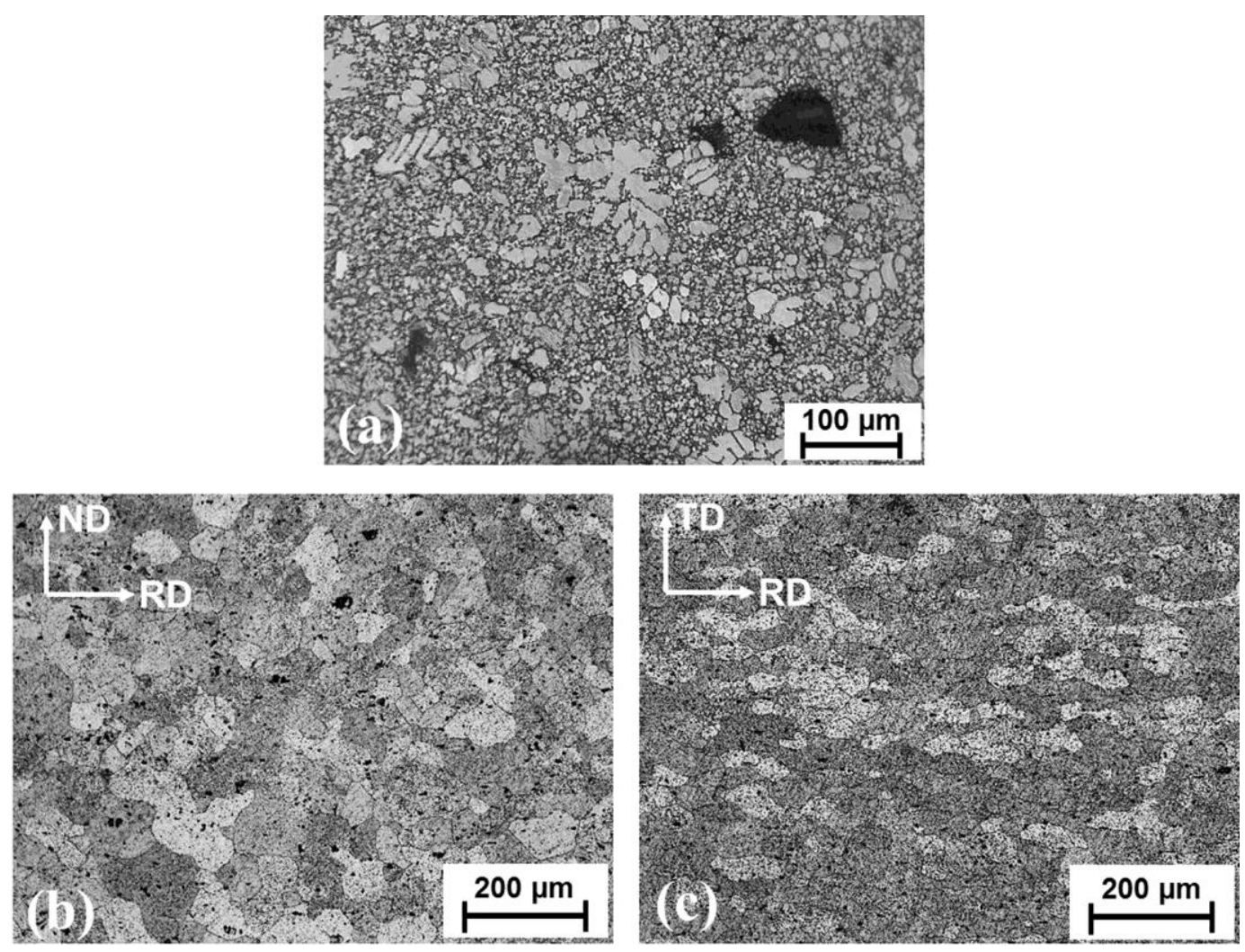

Fig. 3. Microstructure of the as-received (a) AM60B, (b) and (c) AA6022-T4 in various cross-sectional views (ND: normal direction; RD: rolling direction; $\mathrm{TD}$ : transverse direction). 


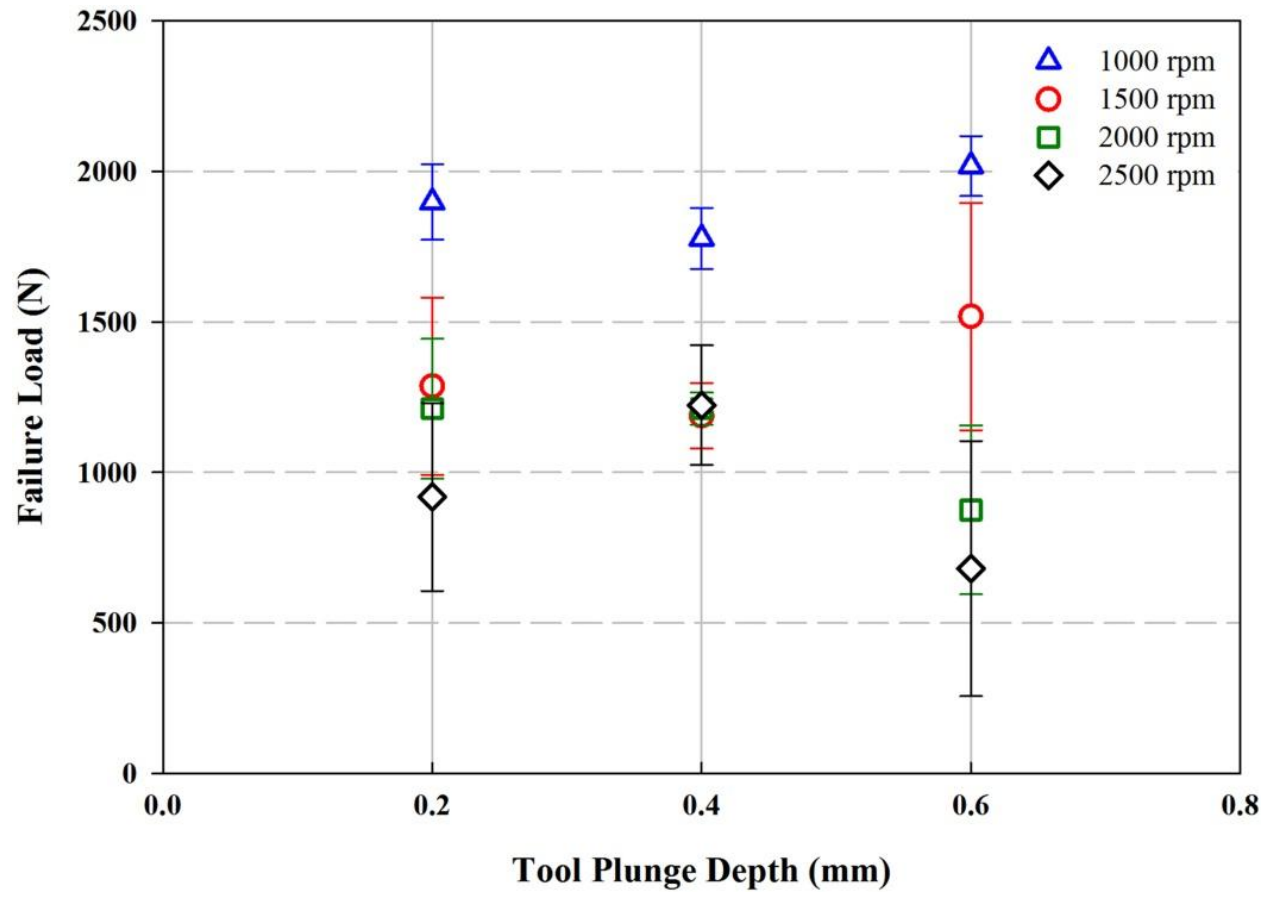

Fig. 4. Lap-shear failure load of welds as a function of tool shoulder plunge depth under various tool rotation rates. 


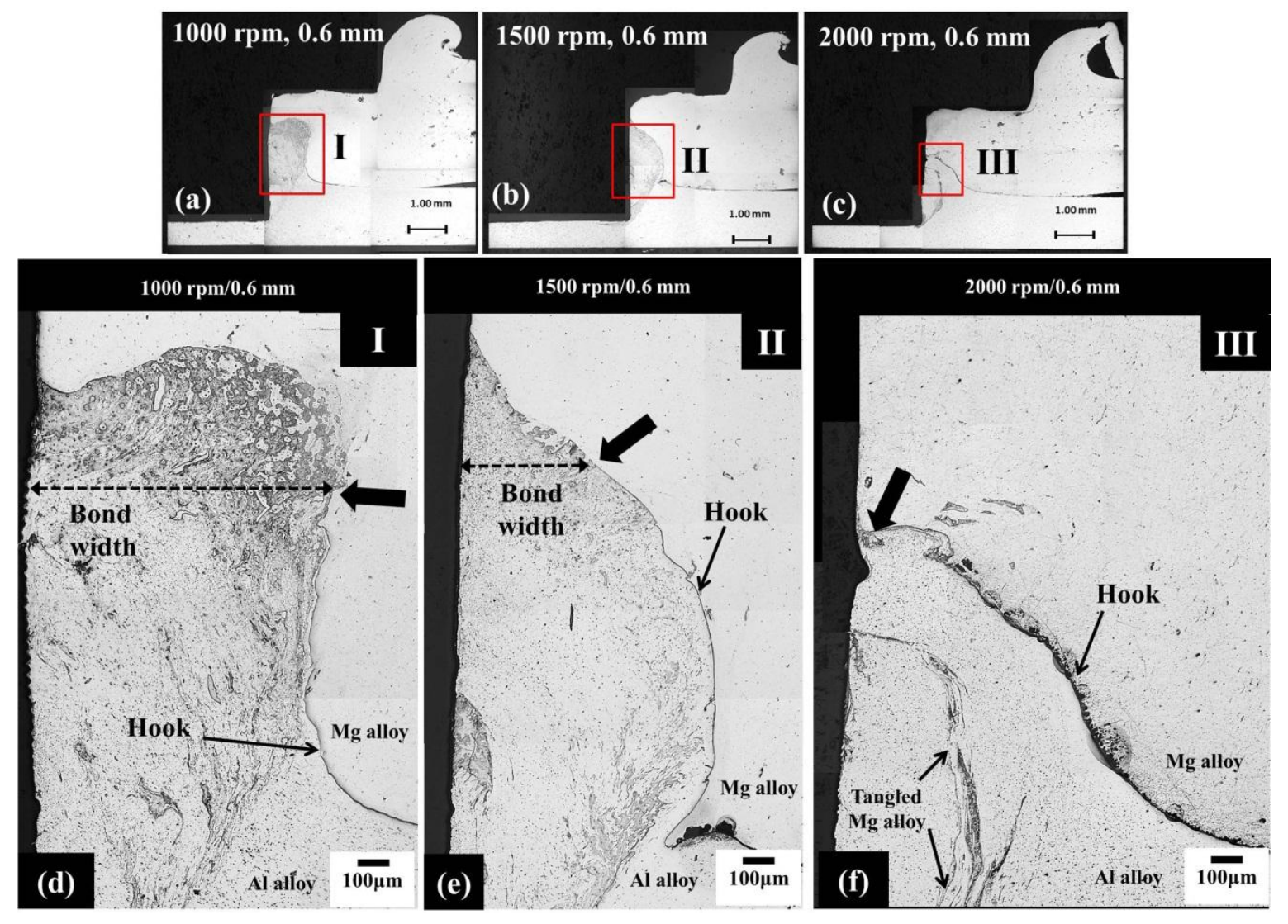

Fig. 5. Representative cross sections of welds made at $0.6 \mathrm{~mm}$ under (a) $1000 \mathrm{rpm}$, (b) $1500 \mathrm{rpm}$ and (c) $2000 \mathrm{rpm}$. Figures (d), (e) and (f) are magnified views of region I, II and III with the bold arrow indicating termination of the hook and the dotted line indicating the weld bond width. 


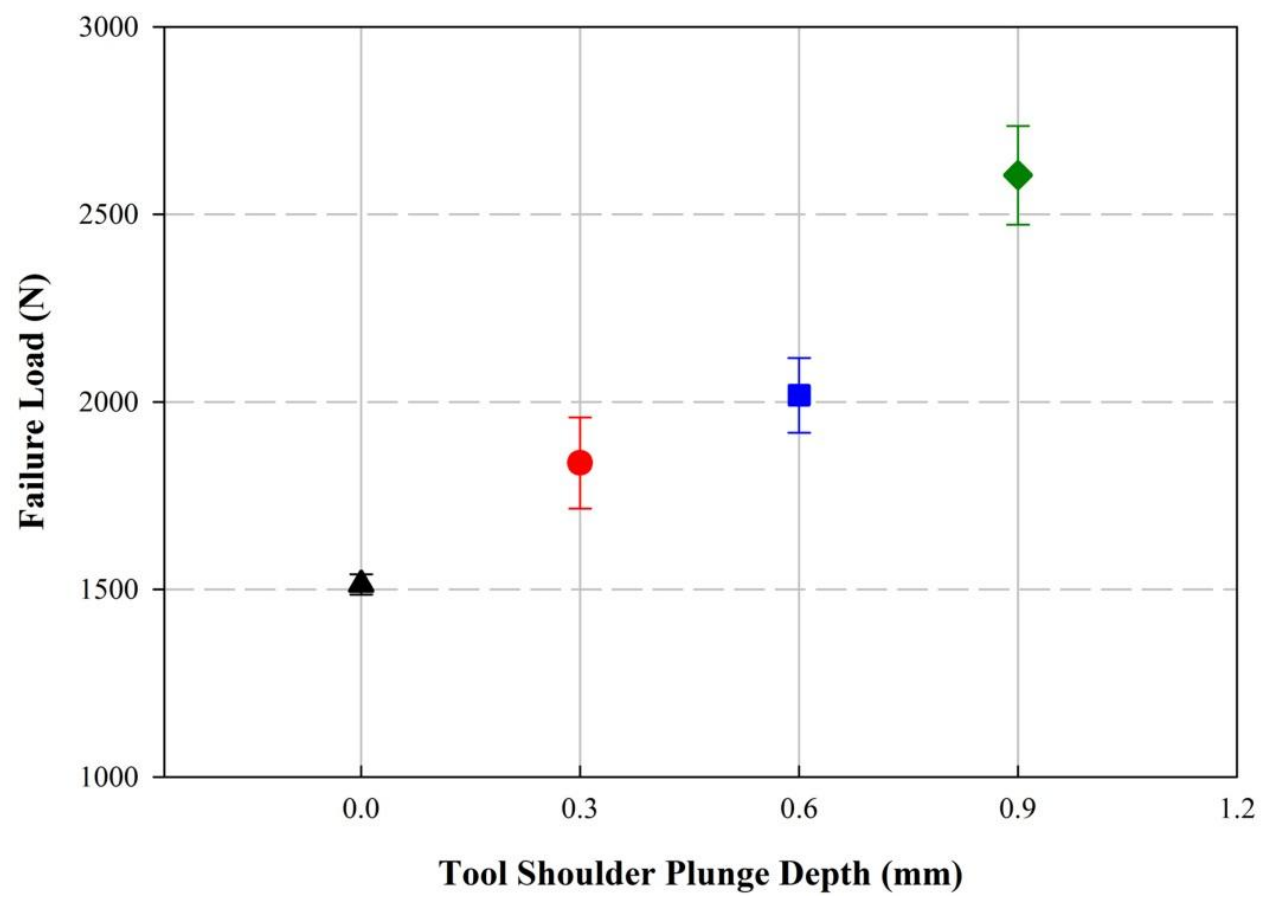

Fig. 6. Lap-shear failure load of welds as a function of tool shoulder plunge depth at 1000 rpm. 


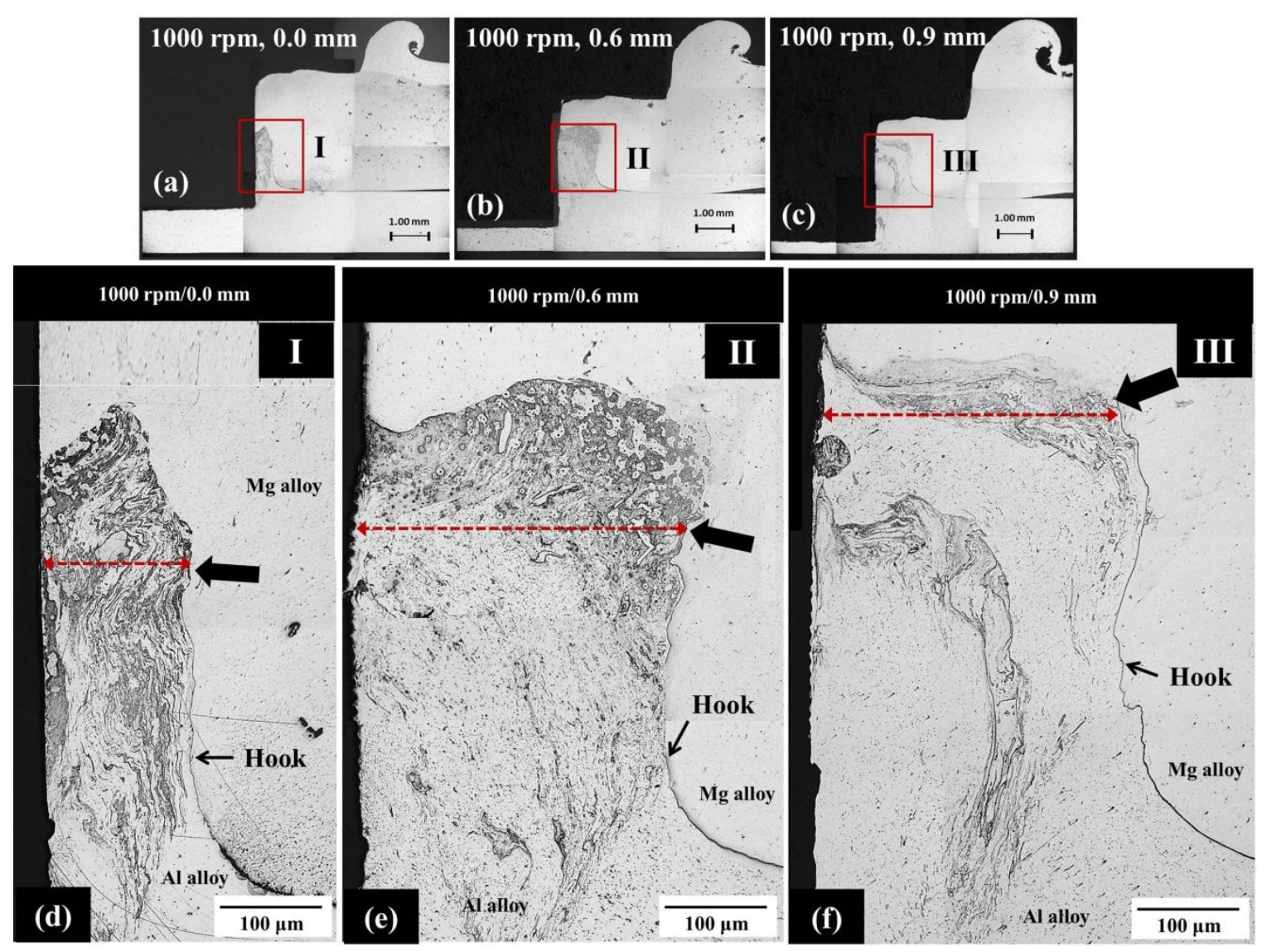

Fig. 7. Representative cross sections of welds produced at $1000 \mathrm{rpm}$ and various plunge depths (a) $0.0 \mathrm{~mm}$ (b) $0.6 \mathrm{~mm}$ and (c) $0.9 \mathrm{~mm}$. Figures (d), (e) and (f) are magnified views of region I, II and III with termination of the hook and the weld bond width highlighted. 


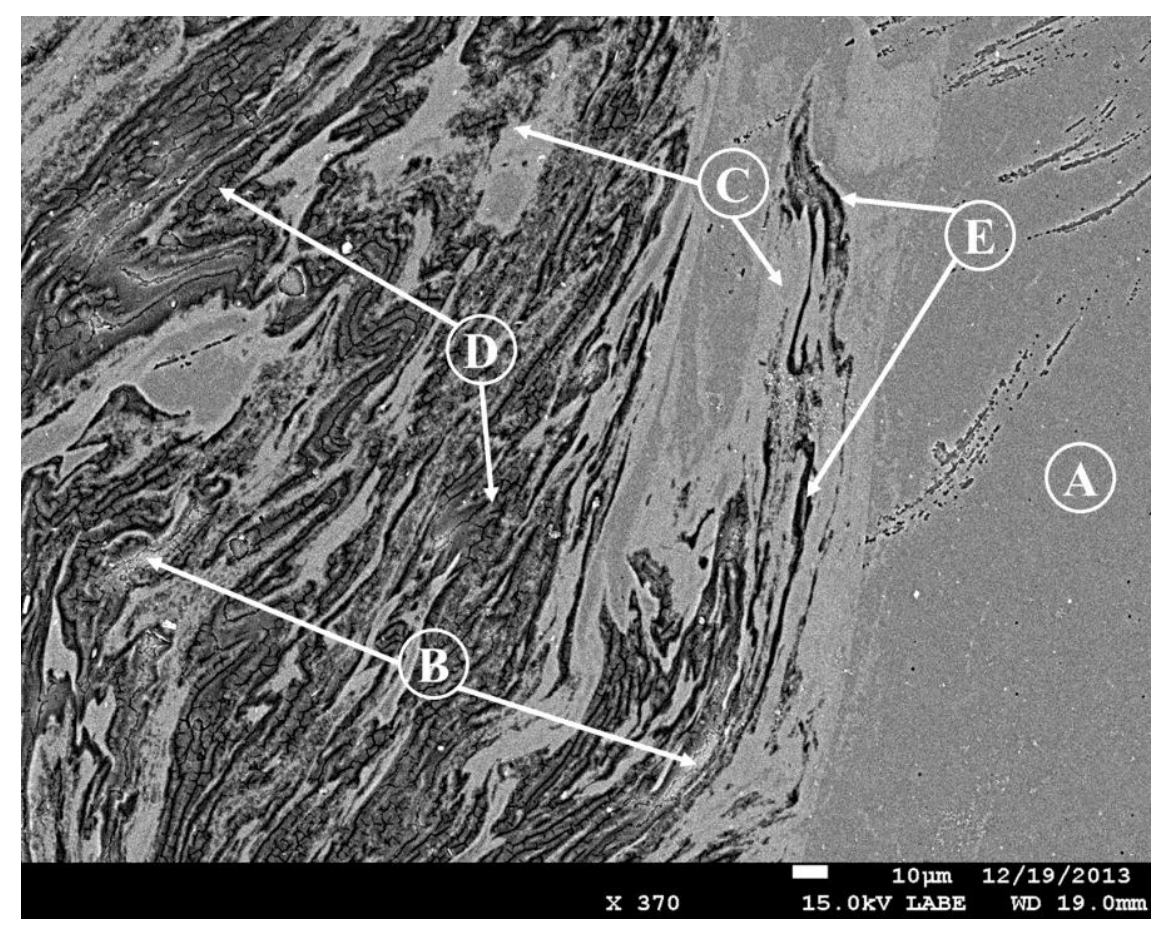

Fig. 8. SEM image showing different regions in the stir zone. Each region is characterized by using EDS with detailed composition shown in Table 3. 


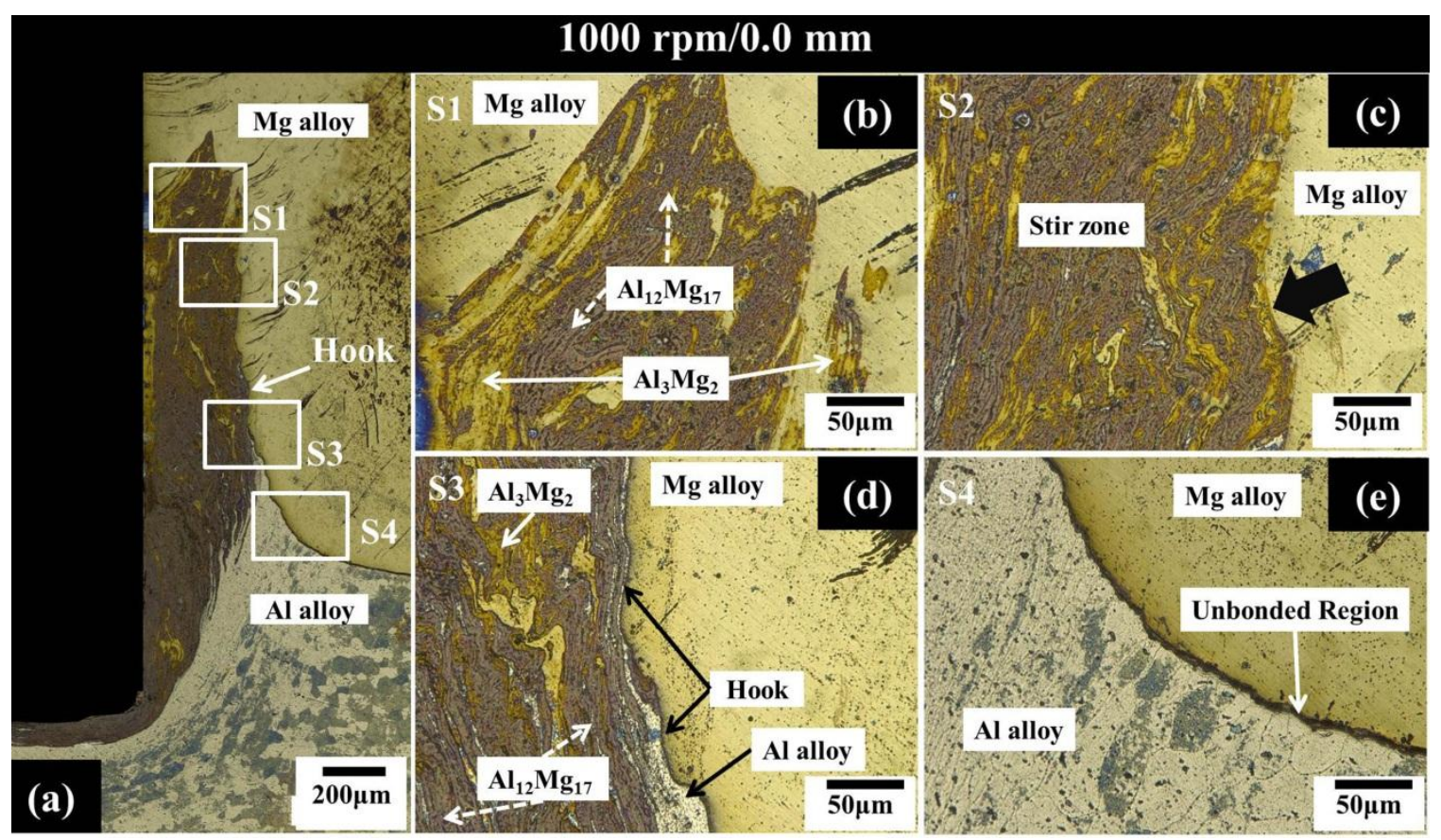

Fig. 9. Microstructure for a weld made at $1000 \mathrm{rpm}$ and $0.0 \mathrm{~mm}$ shoulder plunge (a) macrograph of cross section, (b) region S1 indicating the interlocking in the weld bond width region, (c) region S2 highlighting termination of the hook, (d) region S3 indicating the interfacial hook and (e) region S4 highlighting the unbonded region. 


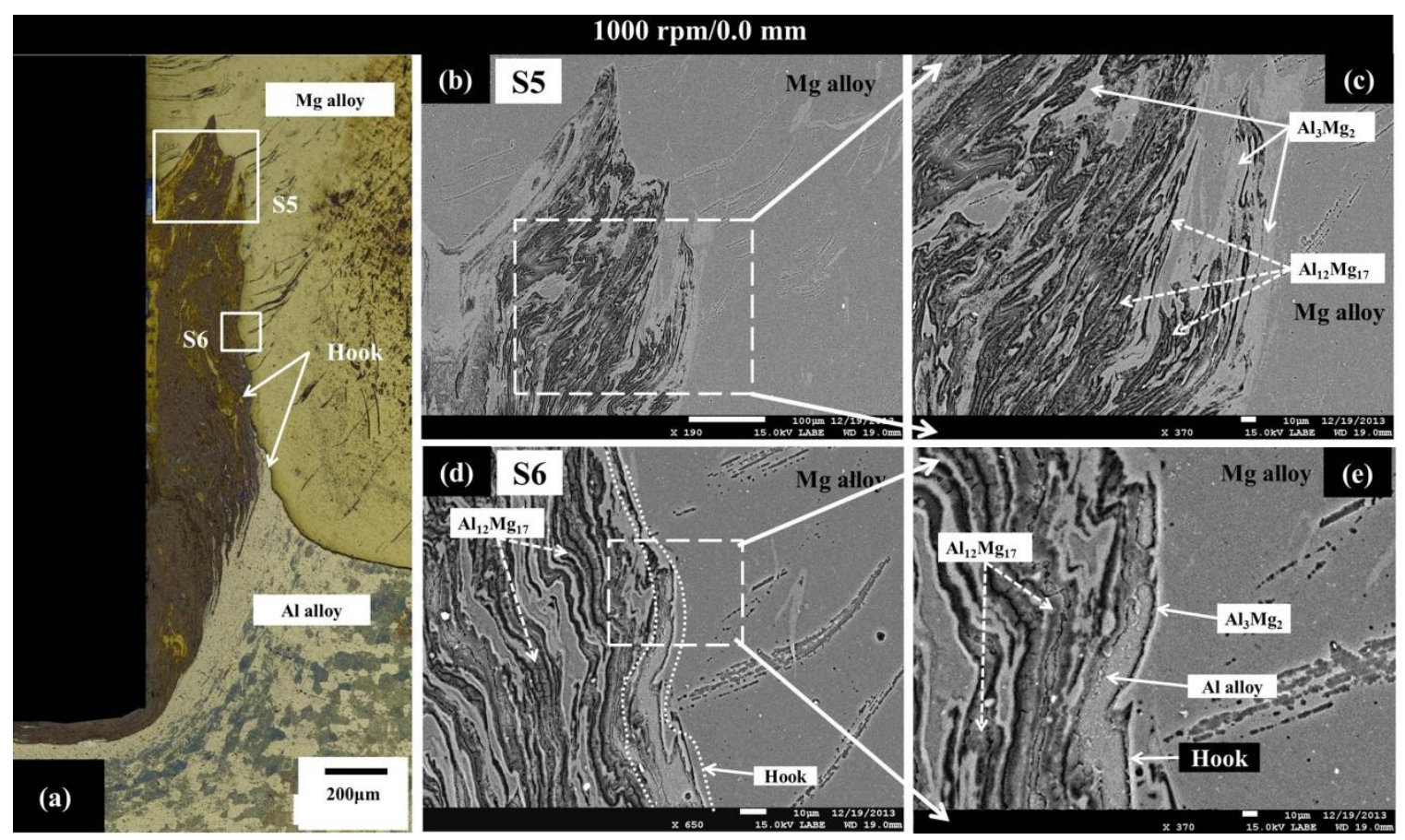

Fig. 10. SEM images of the weld produced at $1000 \mathrm{rpm}$ and $0.0 \mathrm{~mm}$ (a) macrograph of cross section, (b) region S5 indicating the interlocking, (c) magnified view of region S5, (d) region S6 indicating the interfacial hook and (e) magnified view of region S6. 


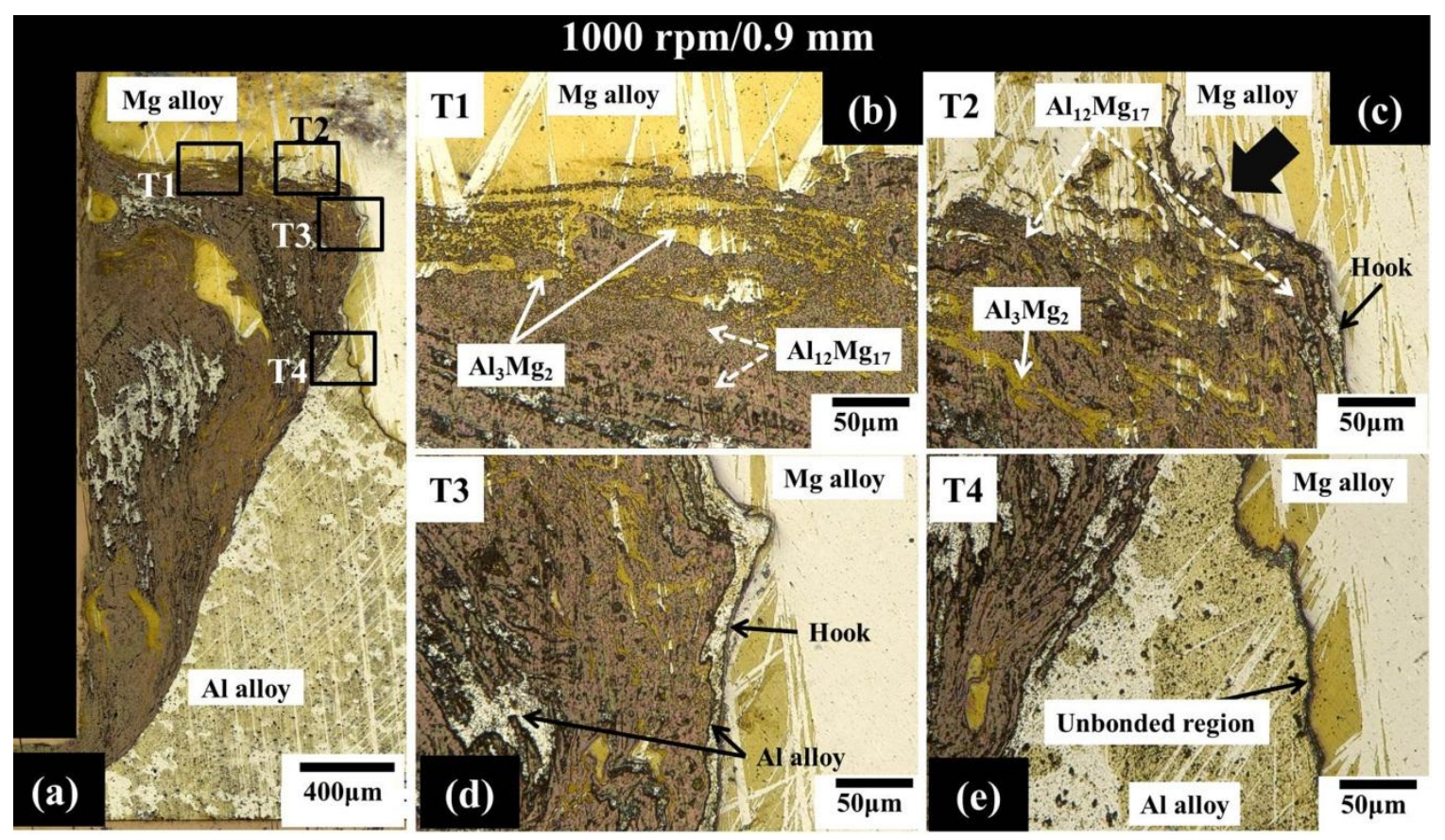

Fig. 11. Microstructures of a weld produced at $1000 \mathrm{rpm}$ and $0.9 \mathrm{~mm}$ shoulder plunge (a) macrograph of cross section, (b) region $\mathrm{T} 1$ indicating the interlocking in the weld bond width region (c) region T2 highlighting termination of the hook (d) region T3 indicating the interfacial hook and (e) region T4 highlighting the unbonded region. 


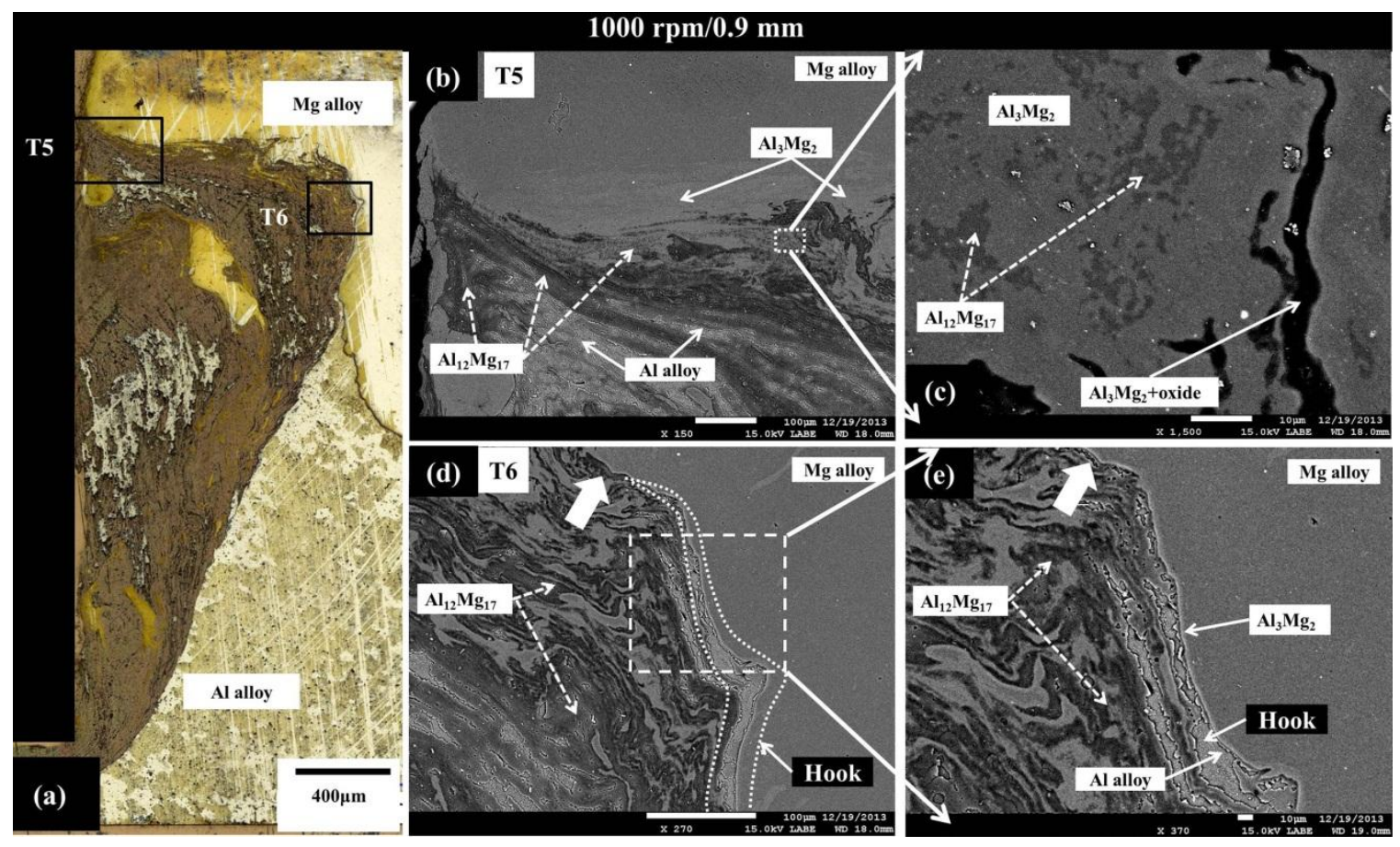

Fig. 12. SEM images of the weld produced at $1000 \mathrm{rpm}$ and $0.9 \mathrm{~mm}$ (a) macrograph of cross section, (b) region T5 indicating the interlocking, (c) magnified view of region T5, (d) region T6 indicating the interfacial hook and (e) magnified view of region T6. 

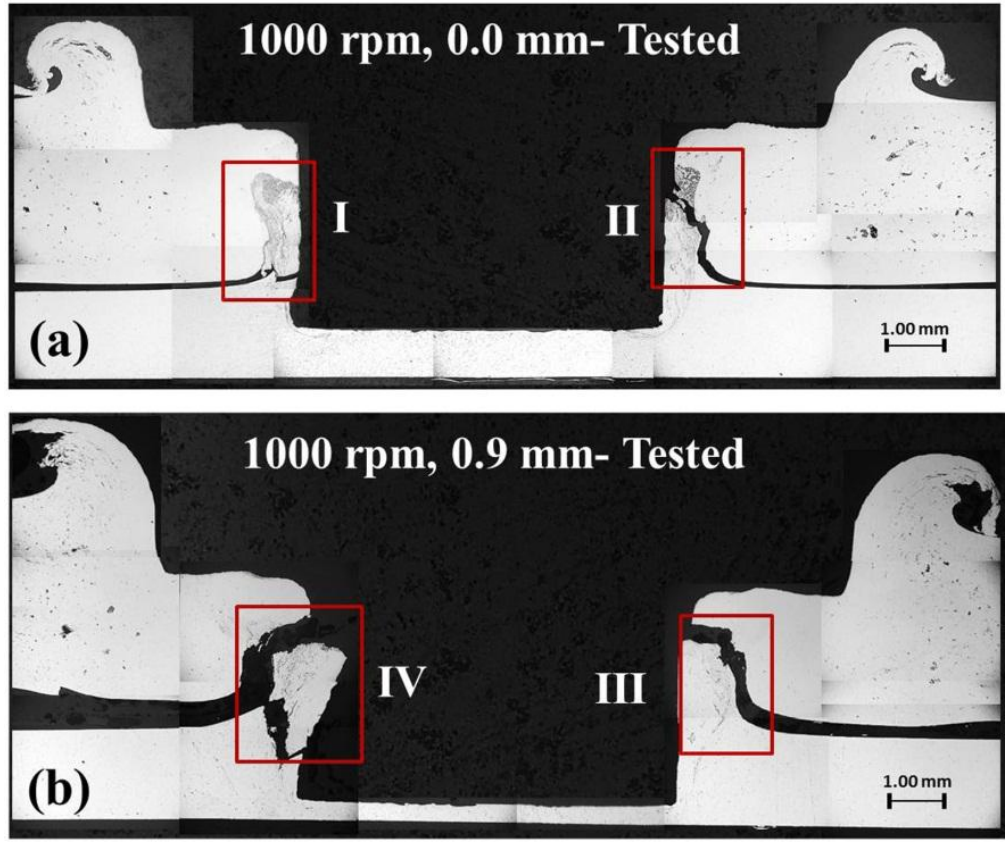

Fig. 13. Cross sections of tested welds made at $1000 \mathrm{rpm}$ (a) $0.0 \mathrm{~mm}$ and (b) $0.9 \mathrm{~mm}$. The boxes in each picture indicate the stir zone where cracks propagated and failure occurred. 


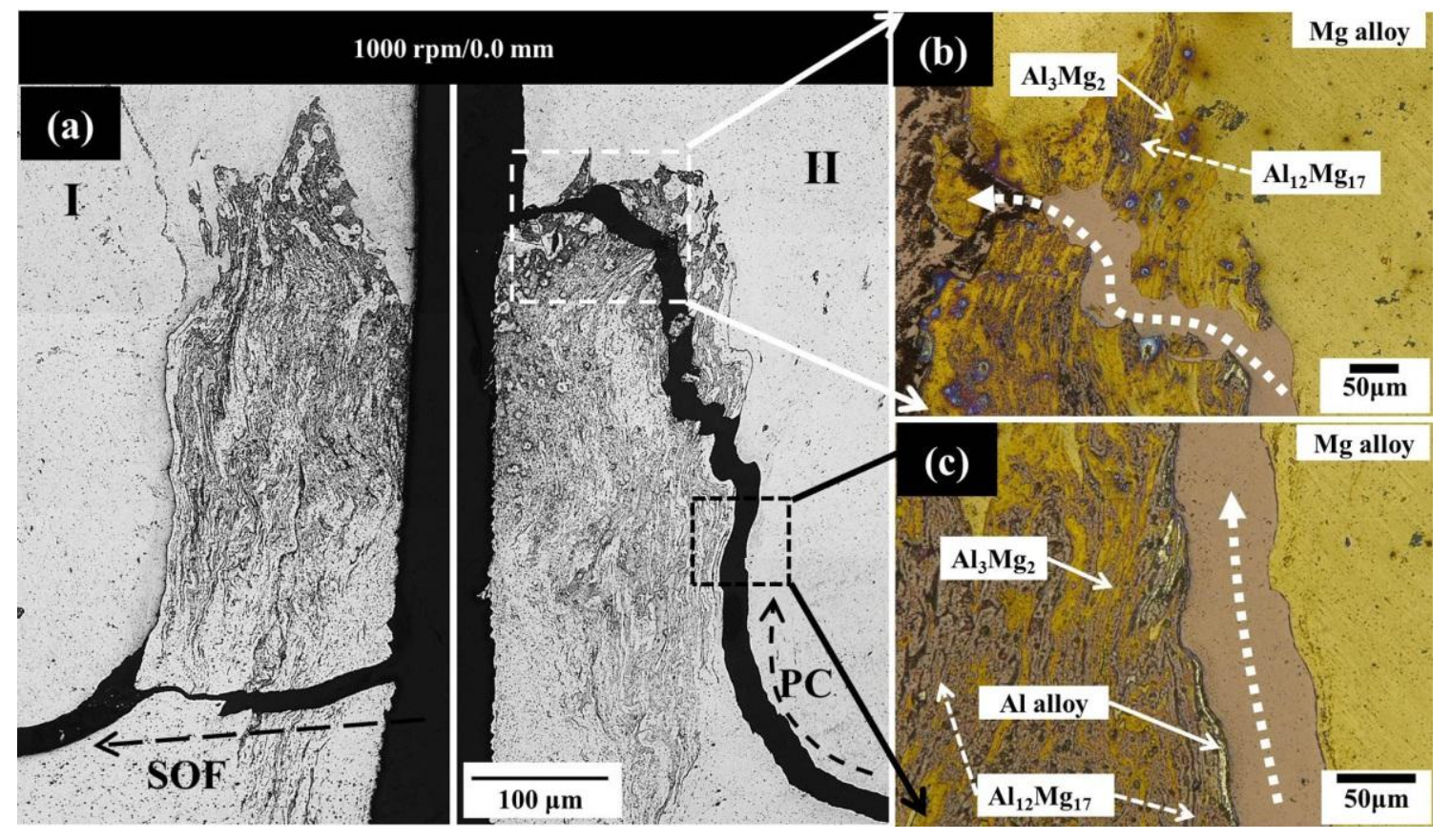

Fig. 14. (a) Macrograph of a tested weld made at $1000 \mathrm{rpm}$ and $0.0 \mathrm{~mm}$ with regions I and II highlighting SOF and PC, and magnified view of (b) the PC propagation in the weld bond width area and (c) the interfacial hook signifying the PC propagation through the IMCs. 


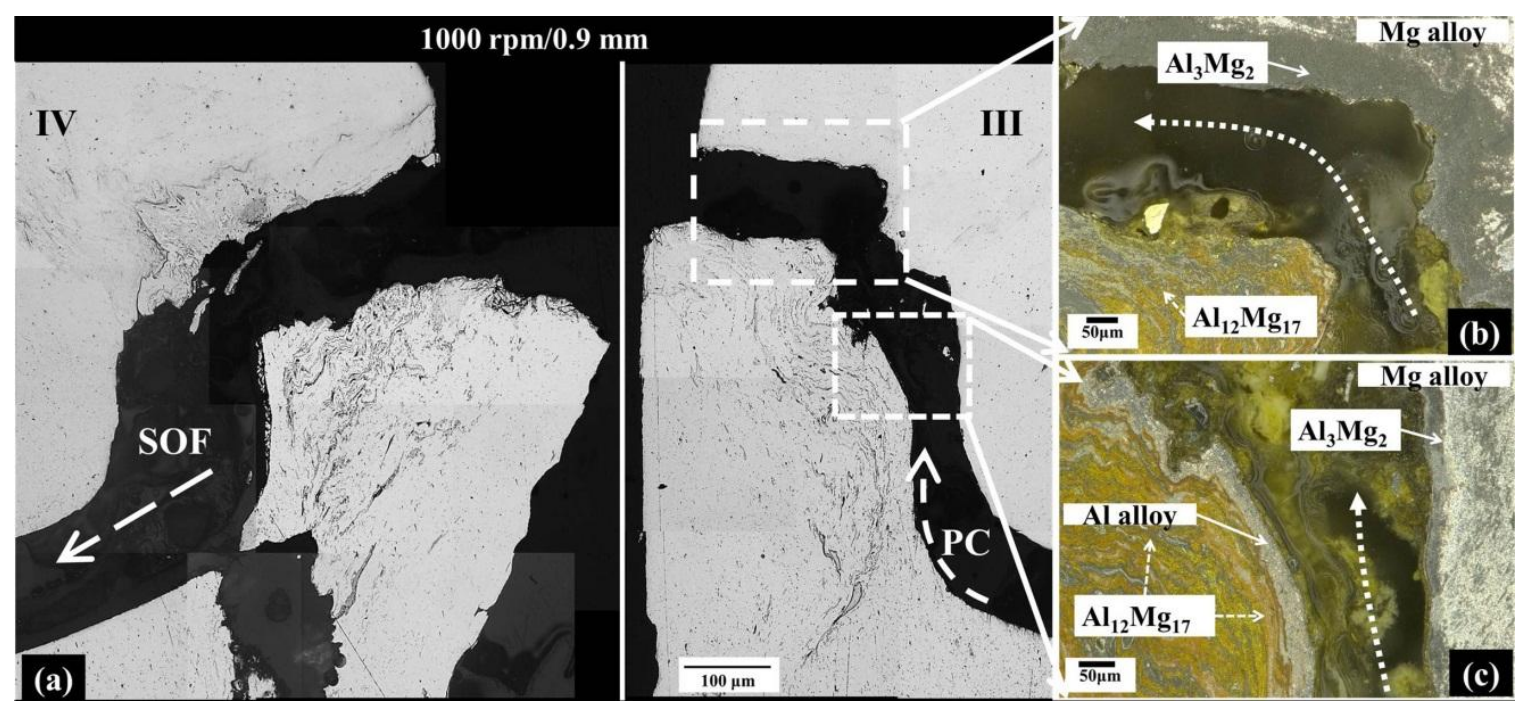

Fig. 15. (a) Macrograph of a tested weld made at $1000 \mathrm{rpm}$ and $0.9 \mathrm{~mm}$ with regions III and IV highlighting SOF and PC, and magnified view of (b) the PC propagation in the weld bond width area and (c) the interfacial hook signifying the PC propagation through the IMCs. 


\section{Tables}

Table 1: Information of tool material and geometric features employed in this study.

\begin{tabular}{l|l|l}
\hline \multirow{2}{*}{ Tool material } & \multicolumn{2}{|l}{ H13 tool steel } \\
\hline & Shoulder shape & concave \\
\cline { 2 - 3 } & Shoulder diameter & $12 \mathrm{~mm}$ \\
\cline { 2 - 3 } Tool profile & Pin shape & Triangular \\
\cline { 2 - 3 } & Pin diameter & tri. $=5.4 \mathrm{~mm}$ (eq.) \\
\cline { 2 - 3 } & Pin length & $3.5 \mathrm{~mm}$ \\
\cline { 2 - 3 } & Pin surface & threaded groove \\
\hline
\end{tabular}

Table 2: FSSW process parameters employed in current study.

\begin{tabular}{cccc}
\hline \multicolumn{4}{c}{ Stage I } \\
$\begin{array}{c}\text { Tool rotation rate } \\
(\mathbf{r p m})\end{array}$ & $\begin{array}{c}\text { Tool shoulder plunge } \\
\text { depth }(\mathbf{m m})\end{array}$ & $\begin{array}{c}\text { Dwell time } \\
(\mathbf{s})\end{array}$ & $\begin{array}{c}\text { Plunge speed } \\
(\mathbf{m m} / \mathbf{m i n})\end{array}$ \\
\hline 1000 & $0.2 / 0.4 / 0.6$ & 1 & 12 \\
1500 & $0.2 / 0.4 / 0.6$ & 1 & 12 \\
2000 & $0.2 / 0.4 / 0.6$ & 1 & 12 \\
2500 & $0.2 / 0.4 / 0.6$ & 1 & \\
\hline \multicolumn{5}{c}{ Stage II } & 12 \\
\hline 1000 & $0.0 / 0.3 / 0.6 / 0.9$ & 1 & 12 \\
\hline
\end{tabular}

Table 3: Composition (weight \%) measured using EDS at various locations in the stir zone.

\begin{tabular}{|c|c|c|c|c|c|}
\hline Region & Phase & $\mathrm{Mg}(\mathrm{Wt} . \%)$ & $\mathrm{Al}(\mathrm{Wt}$ \%) & $\mathrm{O}(\mathrm{Wt}$ \%) & Total \\
\hline $\mathrm{A}$ & $\mathrm{AM} 60 \mathrm{~B}$ & 90.43 & 8.96 & 0.65 & 100.0 \\
\hline $\mathrm{B}$ & $\mathrm{AA6022}$ & 0.96 & 98.54 & 0.51 & 100.0 \\
\hline $\mathrm{C}$ & $\mathrm{Al}_{3} \mathrm{Mg}_{2}$ & 36.74 & 61.8 & 1.46 & 100.0 \\
\hline $\mathrm{D}$ & $\mathrm{Al}_{13} \mathrm{Mg}_{17}$ & 79.82 & 19.28 & 0.9 & 100.0 \\
\hline $\mathrm{E}$ & $\mathrm{Al}_{3} \mathrm{Mg}_{2}+$ Oxide & 13.45 & 67.74 & 18.81 & 100.0 \\
\hline
\end{tabular}

